\title{
Applying the Leadership Traits Approach to Volunteer-based Community Media
}

\author{
Sam Chege Mwangi, Kansas State University, USA \\ Bonnie Bressers, Kansas State University, USA \\ Stephen Smethers, Kansas State University, USA
}

\begin{abstract}
The role that leadership plays in the success or failure of community media organizations is an under-researched area. The concept of leadership in this paper refers to positive influence that moves a group towards its goals and is different from management because it relies on social influence rather than legitimate power to influence people. Focusing on the case studies of two community media organizations in rural Kansas, USA, the paper uses the Kirkpatrick and Locke model of leadership traits to examine the leadership qualities exemplified in these two organizations. The paper found evidence of all the six traits described in the model (drive, leadership motivation, honesty and integrity, self-confidence, cognitive ability and knowledge of business) present in both case studies. The paper also contributes to the further refinement of the model by identifying two other extra traits that ought to be considered in future community media studies.
\end{abstract}

Keywords: Community media, Leadership, Volunteer-based media, Citizen journalism, Leadership traits. 


\section{Introduction}

Leadership is an important factor in any successful media company, regardless of its size. An organization needs effective leadership in order to survive the realities of an ever-changing media marketplace. The "vision" of managers is an essential trait that often determines success or failure of a company, and it can be argued that effective leadership transcends market size; that is, any organization in a large or small market must have good leadership to survive the realities of changing technologies and audience demographics (Sohn, Wicks, Lacy \& Silvie, 1999). Those industry trends have proven to be an uncomfortable reality in all media markets, but it can be argued that these changes are even more unwelcome in rural markets, where community media organizations also face population declines and growing decay in their business communities. Navigating a rural newspaper or electronic media operation through such a storm arguably requires leadership that is as resourceful and farsighted as that which can be found in large market counterparts.

As Kung (2006) has written, few scholars have examined the role that leadership plays in the success or failure of community media outlets, which would seem to be a gross oversight, given the above-stated market challenges. As market factors get more and more demanding, the role of leadership becomes more and more important if local media are to survive as the informational locus of their communities. This paper examines leadership traits and styles of mangers of two unique rural Kansas community media organizations. One outlet is a semimonthly newspaper in a small northwest Kansas town of just over 400 residents, while the other is a unique multimedia production hub in a community of 900 that produces telecasts of local high school sports and other community-oriented videos, as well as doing corporate production work for regional clients. The truly unique aspect of each company is that fact that their products are largely the creation of staffs primarily composed of volunteer labor. Each organization is managed by a local visionary, who must recruit and develop local talent and keep the volunteers focused on the tasks unique to producing the local media product.

\section{The Prairie Dog Press}

Almena, Kansas, is an agricultural community that manages to maintain a small business district, local schools, churches and essential utility services. At the center of Almena's livelihood is a semi-monthly newspaper, the Prairie Dog Press, which was formed in 1995 after the town lost its century-old newspaper, the Almena Plaindealer, when publisher Hemi 
Moody could no longer perform the tasks associated with editing and producing a letterpress newspaper (the Plaindealer was the last paper in Kansas published by that method). Without a newspaper, the community suffered from an information vacuum, as attempts to inform the public about important community events-including a bulletin board in the post office and announcements in the neighboring Norton Telegram-proved to be largely ineffective. The communications void proved to be so debilitating to maintaining important community functions that civic leaders held a series of meetings to explore solutions to the problem. The answer, they decided, was to form a volunteer group to publish a new local newspaper (Bressers, 2000).

Since no one in town had primary knowledge of the newspaper business (save for Moody, who promised to support volunteer efforts but did not wish to be a part of the staff), the new group decided to transform themselves into makeshift journalists. They sought help from a community media resource center at Kansas State University, and student volunteers moved into the town for a month to teach willing townspeople how to produce a newspaper. Additional volunteers decided to try their hands at reporting and writing news stories and local opinion columns (Robonson, 2005). The fledgling staff named the publication the Prairie Dog Press, an appellation derived from Prairie Dog Creek, a waterway that runs through the town (Bressers, 2000). The Press's composition and publication was initially managed by two local residents, Becky Madden and Laura Craig, who served as co-editors. After a short while, Madden left the staff, and Craig, who was barely oriented to the demands of newsgathering, copy editing and using a computer for writing and laying out the paper, emerged as the Press' editor, a position she has now held for 21 years (Laura Craig, personal communication, June 22, 2016).

The newspaper's survival for over two decades, especially as an all-volunteer organization, is a working arrangement that begs for further study. Even Editor Craig, who has managed the paper from the beginning, has received no financial compensation. "It's a labor of love," said Craig. "If I start getting paid, then it becomes a job" (Laura Craig, personal communication, June 22, 2016). Craig has consistently recruited local laypersons and turned them into writers, copy editors, printers and circulation managers, and most of the talent has been developed from the echelons of Almena's senior citizens (Craig reports that currently, the youngest staff 
member is in her 60s). The management style that Craig provides to motivate her staff to donate their time to the publication, certainly emerges as a leadership style worthy of study.

\section{The Kiowa County Media Center}

The Kiowa County Media Center in Greensburg, Kansas, similarly grew from an arguably greater communication need. On May 4, 2007, the small South Central Kansas town was hit by a devastating EF-5 tornado that virtually destroyed the city. The storm's aftermath saw this community of just over 1,500 with almost no communications system, since the electrical and cable TV systems were destroyed. Logistics mostly prevented area radio and television stations and newspapers from filling the information void at a time when constant communication was vital ("Greensburg is Gone," 2007). As the community slowly rebuilt, local leaders were mindful that the new Greensburg needed a better communications infrastructure to warn its citizens of severe weather and to provide a system that would better fill future emergency information voids. City and county leaders held subsequent meetings with representatives from a major state university to brainstorm solutions to the problem. The answer: a state-of-the-art multimedia communications center, with a mission to provide pertinent local information via a portal distributed through an advanced WiMAX broadband network. The KCMC was to be housed in the Kiowa County Commons, a structure also designed to provide space to replace the Greenburg City Library, the Kiowa County Historical Society Museum and the county Extension office. The two-story building's second floor was built to contain a television studio, editing bays, audio production facilities and offices for staff members (Smethers, Freeland \& Rake, 2010).

Organizers initially dreamed of a grand experiment in community media: an open-source communications hub, where local residents could furnish audio, video, photo and textual content for the information portal. Local residents of all ages, it was theorized, would readily take advantage of the opportunity to learn the skills associated with audio and video production and provide content. Planners provided a budget for a Center director, who would regularly teach classes designed to turn laypersons into producers. Community residents initially registered a positive attitude towards the idea; in fact, focus groups conducted with city and county residents indicated a willingness to participate, providing that instruction would be available (Smethers, Freeland \& Rake, 2010). However, the open-source project did not reach fruition. In 2011, the Center's Board of Directors hired Grant Neuhold, a video 
production specialist, as the project manager charged with making the hoped-for mission a reality. Neuhold was able to recruit some high school students and a few adults to produce some informational features, but it soon became evident that the KCMC citizen's journalism idyll was not sustainable. In fact, a community survey in 2012 revealed that while a majority of county adult residents believed the KCMC to be beneficial, they also saw that technical skills were a major inhibiting factor to involvement, and few persons felt that they had the time to learn video storytelling skills (Mwangi, Smethers \& Bressers, 2014).

The resourceful Neuhold realized that he needed to prove the KCMC's potential worth to local residents by launching a production project that would simultaneously affect peoples' lives while potentially involving a wide variety of community residents in the Center's educational and production outreach. Neuhold understood that local sports are always a popular activity in a small town, so he embarked on an ambitious project: recruiting a staff of mostly adult volunteers, who, assisted by some high school students, to produce Kiowa County High School athletic events, streamed to area audiences via the Internet. The cadre of volunteers quickly coalesced into a collegial group who produced highly professional telecasts, and the streamed sports broadcasts have become popular among local audiences (Grant Neuhold, personal communication, June 22, 2016).

Since its inception, KCMC operational expenses have been underwritten by the Kiowa County Commission, a financial arrangement that is at best tenuous, since frugal members of the governing body are continually seeking ways to cut the county budget (in fact, Neuhold estimates that the media center's budget has been cut by an average of $\$ 5,000$ each year). Faced with the need to generate revenue, Neuhold realized that few commercial video production houses exist in the South Central and Southwest Kansas region, meaning that there was a ready market for corporate videos, live events streaming, web design, IT services and phone and tablet repair services. He immediately began recruiting corporate clients, and several regional companies have become regular KCMC customers. The customer base has provided a financial cushion and allowed Neuhold to hire a small staff to help him manage KCMC's myriad of services and develop further revenue-producing options, but the staff is not sufficient to provide the necessary labor to meet the Center's production demands. Neuhold has had to recruit and develop talent from the community, which has also been a 
combination of adult and high school student volunteers (Grant Neuhold, personal communication, June 22, 2016).

Maintaining a demanding production schedule with a mostly volunteer staff is a challenging proposition. Neuhold's personal contacts in Greensburg and Kiowa County, along with an outreach to local high school journalism classes and other community service programs, has so far netted a good base of volunteers to maintain KCMC operations. And Neuhold has been successful in leading the organization. A study conducted in 2014 found that Neuhold's leadership in first recruiting and then teaching video production principles to the volunteers was essential in making the project work (Bressers, Smethers \& Mwangi, 2014). Understanding the leadership qualities to motivate people to volunteer and perform challenging video production tasks would certainly be prescriptive for similar community based media firms.

\section{Literature Review}

The role that leadership plays in the success or failure of community media organizations is an under-researched field (Kung, 2006). Indeed leadership has been described as one of the most neglected areas of research in the field of media management (Mierzjewski \& Holifield, 2006). The few studies on leadership issues in media industries have focused on topics such as relationship between leadership and change (Gade, 2004; Killebrew, 2003; Perez-Latre \& Sanchez-Tabernero, 2003), organizational problems (Sylvie, 2003), and organizational values and priorities (Demers, 1993, 1994, 1996; Edge, 2003); however, little research has focused systematically on media leaders in particular. The concept of leadership in this paper refers to positive influence that moves a group towards its goals (Catt \& Miller, 1985). Leadership is different from management because it relies on social influence rather than legitimate power to influence people (Powers, 2006).

A long-standing debate on what constitutes leadership includes individual traits, behaviors and styles, interaction patterns, organizational culture and environmental contexts as important contributors to effective leadership (Burns, 1978). Another contested area of inquiry is the very definition of leadership with the most common definition focusing on the extent to which a leader's organizational unit performs its task successfully where such success might be measured in terms of sales increase, profit margin, productivity, or market 
share. Much of the research on leadership has focused on company or government level leadership and dwells on human resource and management issues (Walton, 1999). Politis (2006) found that there had been very few studies that had focused on the issue of leadership at the sectoral level such as the media industry. A rare sectoral study focusing on the media industry found that the leadership characteristics profile for those in the media industry must mirror the transformational changes shaping the industry which is undergoing massive structural changes caused by technological developments affecting production processes, organizational structure, the products and market positions (EU, 2002). The changes in the media industry are also dependent on parallel developments in other fields such as information technologies and new structures for production workflows (Comprint, 1998). Given these transformational changes, some of the ideal leadership characteristics valuable for those in the media industry would include the ability to create a vision and provide strategic thinking, motivation of stakeholders, teamwork, decision-making capability, ability to communicate with other people, and ability to create and maintain effective relations with key players relevant to the media sector. Ferrucci (2015) argues that as technology continues to enable various models of journalism to emerge, it is important to understand how leadership impacts the culture of a media organization. Newsroom leaders have great impact on the organization culture and work processes that emerge under their leadership as they provide the vision, resource allocation, power, and organizational structures and processes (Tuchman, 1978; Paterson \& Domingo, 2008Schein, 2006). Gans (1979) found that in media organizations owned by large corporations, newsroom leaders usually executed the vision of the corporate office. Schultz (2007) observed that in the digital age, news values have shifted to reflect the vision of the leadership.

Non-media Studies that have sought to create a profile of characteristics of successful leaders in organizations and industries tend to straddle a host of many areas with a heavy focus on demographics. Chandy (1991) focused on the age, education, and family background, as critical influences that such leaders bring along in their strategic direction for their organizations. Noel (1989) used ethnographic techniques to argue that an individual's early passion affects a firm's vision and focus, while another study looked at the early influences of leaders including their place of birth and their educational majors as having critical impacts on a leader's vision and strategy (Boone and Kurtz). Another study that sought to create a profile of the characteristics related to the strategic performance of media firms found some 
telling demographic predictors for success including a leader's primary occupation, gender, and number of years as CEO (Shaver, 2006).

Some scholars dating back to the $20^{\text {th }}$ century have been fascinated by the leader's traits approach (Stogdill, 1948; Lord, DeVader \& Alliger, 1986; Kirkpatrick \& Locke, 1991; Cawthon, 1996) and seeks to find the answer to the question: 'what attributes must an individual possess to perform effectively in organizational leadership roles ' (Mumford et al, 2000: 156). This approach conceptualizes leadership as a set of properties possessed in varying degrees by different people (Jago, 1982). The trait approach holds three general assumptions. First, it asserts that individual differences result from the differences in the strength and combination of traits. Second, personality traits are relatively stable over time: inborn and innate characteristics of person are enduring, they can hardly change. Third, personality traits are consistent over situations, and there are universal traits that can be effective in all the situations (Jago, 1982).

In recent years, there has been a resurgence of interest in "traits" research which suggests that effective leadership is strongly associated with personalities who seemed to posses certain qualities that could be nurtured (Lord et al, 1986, Bryman, 1992, Kirkpatrick \& Locke, 1991) or what Kirkpatrick and Locke call "the right stuff” (1991: 59). Hang (2006) argues that the need for leaders to have "the right stuff" also applies in media companies. Recent studies have begun to develop a list of that "right stuff" or leadership traits which has culminated in the Kirkpatrick and Locke model based on traits (1991). The model contains the following six traits important to leadership success: drive, leadership motivation, honesty and integrity, self-confidence, cognitive ability and knowledge of business. Drive refers to the effort that a leader brings along to the job while leadership motivation refers to the willingness to lead. Honesty and integrity confers credibility to the leader while self-confidence earns a leader respect among his followers. Cognitive ability is important for problem solving and formulating strategy while knowledge of business guides the cognitive skills. The list of traits in this model is not exhaustive and does not include such traits as charisma or flexibility, but sets out critical preconditions for leaders that are necessary for decision making.

Thus the Kirkpatrick \& Locke model seems to lay the necessary preconditions for effective application of the path-goal theory of leadership which looks at how the leader interacts with 
the many variables in the work environment to react to different situations by providing guidance, coaching, motivation, rewards and punishment. The path-goal theory differentiates between relationship-oriented leaders who focus on nurturing friendship, trust and respect between them and their subordinates and the task-oriented leaders who are more focused on getting the job done (Rue \& Byars, 1986). The theory further argues that personal characteristics including age and work experience influences how a leader behaves towards his subordinates. Workers who have more work experience and higher education value leaders who are more relationship-oriented. Another variable that the theory considers is the organizational environment such as task structure, market size or staff size. When tasks are clear, relationship leadership tends to develop. Task oriented leadership tends to develop more in manufacturing facilities where there is pressure to produce (Schreisheim \& Schreisheim, 1980).

Using the Kirkpatrick \& Locke traits model, this research seeks to find out:

RQ1: To what extent are each of the leadership traits exemplified in Almena and Greensburg case studies?

RQ.2: To what extent, if any, does leadership in the Almena and Greensburg case studies suggest the presence of other relevant leadership traits?

\section{Methodology}

This study attempts to answer the research questions using two different methods: in-depth interviews and focus groups, which were conducted between 2013 and 2015 in the two communities that are the locus of this study, Almena and Greensburg, Kansas. Subjects were comprised from two groups of people: 1) the managers profiled in this study, Laura Craig, editor of the Prairie Dog Press in Almena and Grant Neuhold, production manager of the Kiowa County Media Center in Greensburg, and persons with primary knowledge of the management styles of the principals in each town. Researchers conducted a series of interviews with Craig and Neuhold, in line with guidelines prescribed by Babbie (1992) and Touten (2011), with open-ended questions aimed at ascertaining the managers' personal motivations and the philosophies that guide the execution of their jobs. Interviews were recorded and manuscripts of their comments were made, using a thematic analysis as stipulated by Boyzatis (1998). 
From the comments made by Craig and Neuhold, a series of questions was created for interviews and focus group studies with staffs of media operations in the two communities. In Almena, researchers conducted focus groups with the production staff of the Prairie Dog Press in the summer of 2014. Nine female respondents answered questions relating to their roles in publishing the newspaper and especially, Craig's leadership style. The group discussion was recorded, transcribed and theme analyzed according to the focus group questions. In Greensburg, researchers conducted two sets of interviews. First, each member of the volunteer production staff that produces local high school game telecasts for the KCMC was interviewed in 2013. Questions centered around subjects' personal motivations for participating and their assessment of Newhold's leadership style. Each interview was recorded and transcribed. A second source of volunteer labor at the Media Center, students enrolled in community service projects in the Kiowa County school system, participated in focus groups conducted by researchers on the Unified School District 422 campus in 2015. Again, respondents (who represented junior high and high school students) were asked questions relating to their personal motivations for volunteering, as well as their assessment of the Media Center and Grant Neuhold's leadership.

\section{Results and Discussion}

Research suggests that the examination of personality traits can contribute to a better understanding of the very essence of leadership (Hang). Unlike ethnographic analyses, this research primarily examines leadership attributes as identified by a critical dimension of the successful media organization: the front-line workers whose ongoing efforts result in a journalistic endeavor utilized by its audience(s) and sustained over time. Additionally, discussion of relevant personality traits as self-reported by two successful leaders of volunteer-based media organizations are reported to provide insight into whether the traits they identify are similar to the traits each set of front-line workers attributes to them. While the six leadership traits explicated by Kirkpatrick \& Locke are not mutually exclusive, the Almena and Greensburg questionnaire responses and depth interviews were examined for indication of the presence of each trait. A second research question sought evidence of other leadership traits thought to affect the success or failure of each media model as identified by both the volunteer workers and the two leaders in question.

RQ1: To what extent, if any, are each of the leadership traits developed in the Kirkpatrick \& Locke model exemplified in the Almena and Greensburg case studies? 


\section{Analysis of Leadership}

\section{Drive}

Kirkpatrick \& Locke frame drive in terms of ambition, business expansion, and high levels of enthusiasm and energy for the work, descriptors that were evidenced, in whole or in part, in both the Almena and Greensburg cases. While the Almena Prairie Dog Press's Craig sought project sustainability rather than expansion, from the onset Greensburg's Neuhold envisioned a growing enterprise offering an increasing array of services as resources become available. Because of the inevitability of ongoing reductions in local-government funding, Neuhold's visions for an expanded Kiowa County Media Center range from providing billable multimedia services to business and other clientele, which quickly became a viable business strategy, to partnerships with the local school district and area community colleges to teach students, recruit workers and encourage contributions of content for distribution via the portal.

Both the Almena and Greensburg volunteers regularly cited the energy, enthusiasm and work ethic of their respective leaders. In Almena, volunteers cited Craig's tireless efforts as a motivation for their own participation. "She just keeps plugging away and we don't want her to do it by herself," said one respondent, while another said communities striving to begin similar initiatives would be well advised to: "Have someone like Laura. They have to find some people who have a passion, like Laura does." Asked if any community could be as successful with a volunteer newspaper as Almena is, another volunteer said simply: "They should be able to. But they've got to have someone like Laura." (July 14, 2014). Similar sentiments were voiced repeatedly by respondents associated with the KCMC, including one who called Neuhold "one of the hardest-working people I've ever been around." (September 10, 2014) Like Almena, KCMC volunteers responded that Neuhold's assiduousness motivated their own volunteer efforts (March 11-19, 2013), a fact Neuhold himself acknowledges and utilizes, "If they see me do it, they’ll pick it up." (March 19, 2013)

\section{Leadership motivation}

Willingness to lead, personal control over the enterprise, and polished social skills that increase the leader's influence are characteristics Kirkpatrick \& Locke ascribe to leadership motivation. Greensburg's Neuhold, asked to describe his leadership style, was matter-of-fact: 
I've actually been a natural-born leader, all the way through school. I just step in to a leadership role without even thinking about it. I feel very comfortable. I don't mind the pressure, people looking to me about what to do next. And volunteers add a whole new element. (March 13, 2013)

Almena's Craig initially took the leadership role to help her cope with family tragedy. Perhaps more circumspect than Neuhold, she nevertheless expressed similar sentiments saying, "The (news)paper is funny. You get sucked in a little at a time and it becomes the reason to get up and do something. I owe the community... It's been a real honor for me to be with the Prairie Dog Press this long. It's been quite a ride.” (May 13, 2014)

Both Craig and Neuhold were instrumental in the early formation of the media projects and both have been widely acknowledged as the leadership, by both their communities and the volunteers, since the projects' inceptions. Both exercise control over their projects ranging from setting goals and agendas to dealing with day-to-day minutae. While Neuhold is advised by a board of directors, "everything starts and stops with me." (July 14, 2014) Both leaders delegate a variety of tasks, but volunteers of both projects question the future sustainability of the projects absent their leaders. "We need to get someone trained in case...if something happened to Laura," said one volunteer (July 14, 2014), a concern made self-evident when the newspaper stopped publishing while Craig was briefly incapacitated. Both leaders echo the leadership succession concerns of the volunteers. "I've thought of that," said Neuhold. "If something traumatic happened and I was in the hospital for months, everything would be put on hold." It would be difficult to carry on if that were to happen." (July 14, 2014) The most immediate danger to the sustainability of the newspaper, Craig said, is "If I walked out in the street and got hit by a truck. I don't think anyone would take over.” (May 13, 2014)

Regarding social skills, the ability and willingness to provide positive feedback and reinforcement emerged as a central leadership trait in both case studies, cited by volunteers and the leaders themselves. Neuhold stresses "how good we're doing" as a vehicle for achieving buy-in on future, more expansive projects. "That positive reinforcement is what people need to come back," he said. "I stay real positive." Asked about Craig's leadership style, the volunteers cited her ability to create a positive environment. Said one: "She always pats you on the back. She always thanks you. She's not forceful or demanding or gets rude or anything." Volunteers in both projects, but especially in Almena, said those social attributes 
help foster an environment where current friendships are sustained and new ones are created which, in turn, helps in the recruitment and retention of volunteers. Working at the newspaper "is a friendship thing, an extended family," said Craig. "There's lots of comraderie, joking and laughing, everyone enjoying everyone.” (May 13, 2014)

\section{Honesty and Integrity}

Kirkpatrick \& Locke suggest that traits associated with honesty and integrity confer credibility and a more predictable and consistent decision and leadership process. Both Almena and Greensburg exhibit a typical small-, rural-town characteristic: Everyone knows everyone. With both the newspaper and the Media Center, that dynamic has been a valuable asset, with both leaders well known to be members of good standing in their respective communities. For example, one Greensburg respondent, speaking of Neuhold's work with students, said "He's a hard-working person with good values and morals....I know the quality of work he will give the students."

In both cases, several volunteers cited an existing friendship with Craig or Neuhold as a primary motivating factor for their volunteering — friendship presumably indicative of characteristics such as honesty and integrity.

\section{Self-confidence}

Self-confidence, which Kirkpatrick \& Locke cite as essential for commanding respect and arousing followers, was evident in both case studies. Both Craig and Neuhold exhibit indications of self-confidence born of experience or longevity or both. While Craig, now in her 70s, was not the first editor, she became a co-editor and shortly after, the sole editor, since the project's early days in 19XX, when a contingent from the state's land-grant university taught desk-top publishing skills necessary for newspaper production and delivery. Neuhold, not yet 30, attended a college with "a tremendous video program" where he got "a great education." (March 13, 2013) In both cases, their expertise and experiences have been amplified by broad support and gratitude from both the volunteers and the communities they serve.

While both leaders exhibited self-confidence during multiple interviews, their sense of being accepted and valued is not a function of being native-born with long family legacies in their 
communities. Craig and Neuhold are both considered "newcomers" in the small-town sense. Said Craig:

There are three types of people who live in Almena. There is the inner circle of those who were born here and raised here and they all know teach other. Then there is the second circle of those who marry into the inner circle but can never belong in the inner circle. Then there's the third circle of those who don't belong here. I was one of those. But since I started doing the paper, I feel like I have become a valuable part of the community.

Neuhold was born and raised in an adjacent state with demographic, social and physical characteristics similar to those of Greensburg. Unmarried during the nascent years of the Media Center, Neuhold has since married a community native and is raising a family there.

\section{Cognitive Ability; Knowledge of Business}

Kirkpatrick \& Locke argue that cognitive ability is the essential trait for problem solving, strategy formulation, and decision making, while knowledge of business, Kirkpatrick \& Locke say, is often even more important than cognitive abilities. Evidence suggests that both Craig and Neuhold, beyond any doubt, have the cognitive ability and business knowledge to lead their enterprises in ways that impress their volunteers. Volunteers repeatedly said their respective leaders' understanding of the day-to-day operations of every aspect of their operations were unique and indispensible. One Almena volunteers readily admitted that she lacked the skills Craig has to lead the newspaper operations and "everybody is the same way." She explained: "I know I couldn't do it. I don't think there's anybody...If someone told me what to put, I could type it in, but putting it on the pages is very hard." Another said that, given the realities of producing a newspaper, "a lot of people don't have a clue that this is done by volunteers. A lot of people think Laura gets paid to do this.” (July 14, 2014)

Neuhold exhibits similar cognitive ability and business knowledge central to the functioning of the high-tech Media Center and acknowledged in a community where such skills are far from the norm. Volunteers repeatedly referenced self-doubt about their technical skills, with both adults and high school volunteers expressing significant initial reluctance to participate "because you're afraid of messing up." (November 11, 2015) But time and again, the volunteers credited Neuhold for having both teaching expertise and contagious confidence in 
the volunteers' abilities — abilities several high-school volunteers said would be valuable in both their personal lives and future careers. (November 11, 2015). Said one seventh-grade volunteer: "Most times I think how young we are and doing this technology. And we have gotten good at it and picked it up. It strikes us how young we were and how good we are at it. (November 11, 2015)

RQ2: What other relevant leadership traits, if any, are present in the Almena and Greensburg case studies?

Kirkpatrick \& Locke acknowledge that leadership traits other than the six in their model may well exist that also support the possibility, if not the likelihood, of successful leadership and, indeed, other such traits were evident in the Almena and Greensburg case studies. For example, both Craig and Neuhold exhibited a sustained ability to present a vision that volunteers rally around at what could be considered evangelical levels that differs from Kirkpatrick \& Locke's six traits. The Almena volunteers expressed myriad reasons for participation - "it gives me something to do" and "I enjoy the fellowship of other girls," for example - but they frequently cited a more visionary understanding of the role of a community newspaper. "Keeping the little paper alive and going is helping our community stay connected," said one. Greensburg's Neuhold overcame initial community indifference to the Media Center (Mwangi, et al, 2015) and instilled an ambitious vision in volunteers, nearly none of whom had prior experiences producing media content. "I think we could be a viable television station," said one typical volunteer, acknowledging that the idea "sounds crazy" and is "pretty far out there." But, she insisted, "I know we could do it." Several volunteers, adult and high-school, acknowledged with pride that the Media Center project is unique in small-town, rural America, adding that it enhances the community's reputation and serves as an example to others. Demonstrating an additional leadership trait, leaders in both case studies demonstrated a level of charisma that went well beyond Kirkpatrick \& Locke's "polished social skills" aspect of leadership motivation. Volunteers for both media endeavors repeatedly cited fond feelings for their leaders that caused them to tirelessly perform tasks essential for operational success, while also being willing to volunteer for additional duties. One Greensburg sports-broadcasting volunteer, asked if he would be willing to work on other projects, said: “Absolutely. Anything Grant asks me to do I'd be more than willing to do. There's nothing I wouldn't absolutely be involved in...If the need arose, and Grant said he 
needed more, absolutely I'd be there." Almena's volunteers, perhaps less effusive, nonetheless repeatedly citing Craig's selflessness and friendship as a motivating reason for their participation.

Volunteers with both media projects frequently cited their admiration and appreciation of their leaders' levels of community engagement in projects other than the newspaper and the Media Center, community contributions that volunteers said encouraged reciprocal participation in the media endeavors. The success that both Laura and Neuhold have achieved also shows that you don't have to be native to the community if you possess the right personality traits for the job. Both have been accepted by their respective communities and Neuhold has recently married from the area and is raising a family; Laura says she feels accepted by the community: “....since I started doing the paper, I feel like I have become a valuable part of the community." Thus being native to a place is not a prerequisite for a community to allow anyone to run their communication hub if that person shares their vision and identifies with the community. This is a critical observation since most community media outlets are local operations designed for a unique geographic location with all its unique peculiarities that define it. And yet the Almena and Greensburg examples seem to suggest that an outsider can lead such an effort if he/she engages with the community and gains their mutual respect and acceptance. The ability to plan a succession may be a missing, yet crucial, trait. Both Laura and Neuhold do not have a succession plan in place, a situation whose seriousness was underscored when Laura was in the hospital and a volunteer had to step up. This means that if anything happens to either of them, the continuity of the Greensburg and Almena community media operations could be at risk.

\section{Conclusion}

Research in community media has primarily focused on the content and goals of such ventures (Lacy, Duffy, Thorson \& Fleming, 2010). While these are obviously important issues to look at, what the Almena and Greensburg case studies show is the critical role that leadership plays in the success or failure of community media organizations. This paper has sought to use the leadership traits analysis as one way to map out the right leadership qualities critical to the success of community media organizations and to focus attention on the need for researchers to pay more attention to leadership in community media studies. 


\section{References}

Babbie E (1992). The practice of social research $\left(6^{\text {th }}\right.$ ed). Belmont, CA: Wadsworth.

Bressers B (2000, Fall). Inside the Prairie Dog Press; Kansas volunteers publish community news after 102-year-old weekly folds. Grassroots Editor, 41:3, 14-17.

Bressers, B., Smethers, J.S. and Mwangi, S.C., 2015. Community Journalism and Civic Engagement in Mediated Sports: A case study of the open-source media project in Greensburg, KS. Journalism Practice, 9(3), pp.433-451.

Boyatzis, R.E., 1998. Transforming qualitative information: Thematic analysis and code development. Sage.

Burns, J. M. (1978). Leadership. New York: Harper and Row.Catt, S.E. and Miller, D.S., 1985. Supervisory management and communication. McGraw-Hill/Irwin. Comprint, 1998. Navigating in the future media markets, Comprint International Report.

Demers, D.P., 1993. Effect of corporate structure on autonomy of top editors at US dailies. Journalism \& Mass Communication Quarterly, 70(3), pp.499-508.

Demers, D.P., 1994. Effect of organizational size on job satisfaction of top editors at US dailies. Journalism \& Mass Communication Quarterly, 71(4), pp.914-925.

Demers, D.P., 1996. Corporate newspaper structure, profits, and organizational goals. Journal of media economics, 9(2), pp.1-23.

Edge, M., 2003. The good, the bad, and the ugly: Financial markets and the demise of Canada's Southam newspapers. International Journal on Media Management, 5(4), pp.227-236.

European Union 2002. An analysis of the forest industry, European Union - DG Enterprise.

Available at: http://europa.eu.int/comm/enterprise/forest_based/printing_en.html, cited 18. August 2005.

Ferrucci, P 2015. Follow the Leader: How Leadership can Affect the Future of Community Journalism. Community Journalism, 4:2, 19-35. "Greensburg is gone; its future unknown.” (2007, May 6). Wichita Eagle. RetrievedMarch 10, 2010, from http://www.kansas.com/2007/05/06/63063/greensburg-is-gone-itsfuture.html

Gade, P.J. and Perry, E.L., 2003. Changing the newsroom culture: A four-year case study of organizational development at the St. Louis Post-Dispatch. Journalism \& Mass Communication Quarterly, 80(2), pp.327-347.

Gans, H.J., 1979. Deciding what news: a study of CBS evening news, NBC nightly news, Newsweek, and Time. Pantheon Books. 
Jago, A.G., 1982. Leadership: Perspectives in theory and research.Management science, 28(3), pp.315-336.

Killebrew, K.C., 2004. Managing media convergence: pathways to journalistic cooperation. Wiley-Blackwell.

Kirkpatick, S.A. and Locke, E.A., 1991. Leadership: do traits matter?. The executive, 5(2), pp.48-60.

Küng, L, (Editor) 2006. Leadership in the Media Industry: Changing Contexts, Emerging Challenges. Jönköping International Business School, Jönköping, ič iẹpiSweden.

Lacy, S., Duffy, M., Riffe, D., Thorson, E. and Fleming, K., 2010. Citizen journalism web sites complement newspapers. Newspaper Research Journal, 31(2), pp.34-46.

Mierzjewska, B., \& Hollifield, C. (2006). Theoretical Approaches in Media Management Research. In Albarran, Chan-Olmsted \& Wirth (Eds.) Handbook of Media Management and Economics. New Jersey. Lawrence Erlbaum Associates.

Mwangi, S.C., Smethers, J.S. and Bressers, B. (2014). "If you build it, will they come? An exploratory study of community reactions to an open source media project in Greensburg, Kansas." Community Journalism, 3:1, 72-86.

Pérez-Latre, F.J. and Sánchez-Tabernero, A., 2003. Leadership, an essential requirement for effecting change in media companies: An analysis of the Spanish market. International Journal on Media Management, 5(3), pp.199-208.

Peterson, C.A., \& Domingo, D. 2008. Making Online News: The Ethnogrpahy of New Media Production. New York: Peter Lang.

Politis, A.E., Leadership Characteristics in the Graphic Arts and Media Sector. Leadership in the Media Industry, p.59.

Powers, A 2006. An Exploratory Study of the Impact of Leadership Behavior on Levels of News Convergence and Job Satisfaction. In Leadership in the Media Industry: Changing Contexts, Emerging Challenges. Jönköping International Business School,

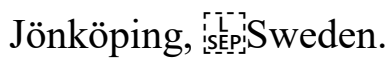

Robinson, R. (Producer). (2005). The Prairie Dog Press: Community journalism's struggle for survival. (Available from the Huck Boyd National Center for Community Media, 110 Kedzie Hall, Kansas State University, Manhattan, KS 66506).

Shaver, D and Shaver, M. A (2006) Credentials, Strategy and Style: The Relationship between Leadership Characteristics and Strategic Direction in Media Companies. In Leadership in the Media Industry: Changing Contexts, Emerging Challenges. 


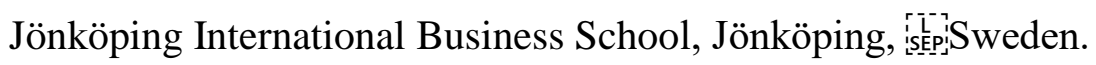

Schein, E.H. (2006). Organizational Culture and Leadership ( $3^{\text {rd }}$ ed.). San Francisco. JosseyBass.

Schultz, I. (2007). "Journalistic Field, News Habits, and Newsroom Capital: Using Reflexive Sociology to Conceptualise Context in Newsroom Ethnography." Paper Presented at the annual meeting of the International Communication Association, San Francisco, California.

Smethers, J.S., Freeland, G.B. \& Rake, J. D. (2010, August 5). "After the storm: Greensburg residents discuss an open source project as a source of community news." Presented in the Community Journalism interest group faculty paper competition, Association for Education in Journalism and Mass Communications, Denver, CO.

Sohn, A.B., Wicks, J.B., Lacy, S. \& Sylvie, G. (1999). Media management: A casebook approach $\left(2^{\text {nd }}\right.$ ed.). Mahwah, NJ: Lawrence Earlbaum.

Sylvie, G., 2003. A lesson from the New York Times: Timing and the management of cultural change. International Journal on Media Management, 5(4), pp.294-304.

Touten, T.L. (2011). "Focus groups and intensive interviews," in Zhou, S., \& Sloan, W.D. (eds.), Research Methods in Communication_(pp. 289-304). Northport, AL: VisionPress.

Tuchman, G. (1978). Making news: a study in the Construction of Reality. New York: Free Press.

Walton, J. (1999). Strategic Human Resource Development. Pearson Education Ltd, Essex. 